\section{Lactate levels as a marker of tissue hypoperfusion in acute heart failure patients seen in the emergency department: a pilot study}

\author{
Kori Sauser, ${ }^{1}$ Lora Alkhawam, ${ }^{2}$ Linda \\ Pierchala, ${ }^{3}$ Peter S. Pang ${ }^{4}$ \\ 'Department of Emergency Medicine, \\ Massachusetts General Hospital, Harvard \\ Medical School, Boston, MA; ${ }^{2}$ Department \\ of Emergency Medicine, Northwestern \\ University, Feinberg School of Medicine, \\ Chicago, IL; ${ }^{3}$ Loyola University Medical \\ Center, Chicago, IL; ${ }^{4}$ Department of \\ Emergency Medicine, Indiana University \\ School of Medicine, Indianapolis, IN, USA
}

\section{Abstract}

Acute heart failure (AHF) may lead to subclinical tissue ischemia due to hypoperfusion from inadequate forward flow or congestion. The aim of the present study is to test whether lactate levels are elevated in emergency department (ED) patients with AHF. A prospective pilot study of ED AHF patients was conducted. Venous lactate level was measured at baseline and 6-12 hours after initial draw. Of the 50 patients enrolled, mean age was 65.3 years, $68 \%$ were male. Only 7 (14\%) had an elevated lactate on either draw, with no differences in baseline characteristics between patients with and without elevated lactate. Patients with an elevated lactate had a higher mean heart rate (99 vs $81, \mathrm{P}=0.03$ ) and trended toward an increased rate of abnormal initial temperature ( 57 vs $23 \%, \mathrm{P}=0.06$ ). In this pilot study, only a minority of acute HF patients had an elevated lactate on presentation.

\section{Introduction}

Heart failure occurs with any impairment in the heart's ability to fill with or eject blood. During acute heart failure (AHF), further deleterious hemodynamic and neurohormonal changes occur, which may lead to tissue hypoperfusion. ${ }^{1,2}$ As myocardial, renal, and liver injury has been observed in AHF, significant tissue injury and organ hypoperfusion may result in elevated lactate levels. ${ }^{2}$ As a marker of poor perfusion, lactate rises with tissue hypoxia. Elevated lactate is used clinically, and serves as a prognostic marker in trauma and sepsis. ${ }^{3}$ In a small study of AHF patients with reduced ejection fraction $(<30 \%), 22$ of
29 patients had elevated lactate levels $\geq 2$ $\mathrm{mmol} / \mathrm{L}$; this suggests AHF patients may suffer from occult tissue hypoperfusion despite no overt clinical shock. ${ }^{4}$ However, this study was conducted prior to the era of natriuretic peptide testing, only included patients with reduced ejection fraction (EF), and did not perform a detailed characterization of patients at baseline, though central venous catheterization was performed. ${ }^{4}$

In this small pilot study, our primary objective was to evaluate whether AHF is associated with subclinical organ hypoperfusion, as demonstrated by elevations in serum lactate, and if so, the magnitude and duration of the elevation.

\section{Materials and Methods}

\section{Study design}

This was a prospective cohort study of a convenience sample of patients presenting with AHF to a single urban emergency department (ED) during the study period of August 2010 through April 2012. The study was funded through an Investigator Initiated Grant from Abbott Point of Care and approved by the Institutional Review Board. The study design, database, data analysis, and final manuscript were independent of the sponsor.

\section{Study population}

Acute heart failure patients were identified within 8 hours of ED presentation. In order to qualify, patients had to have signs and symptom of $\mathrm{HF}$ resulting in a primary diagnosis of $\mathrm{AHF}$, were $>18$ years of age, and had an initial B-type natriuretic peptide (BNP) $>200 \mathrm{pg} / \mathrm{mL}$. Patients with ongoing acute coronary syndrome or troponin elevation greater than three times the upper limit of normal, dialysis dependent, new devices or surgery within the last 30 days, enrolled in an investigational agent or therapy in the last 30 days, unable to provide informed consent, and currently pregnant or up to 60 days post-partum, were excluded.

\section{Study protocol}

After providing written informed consent, a venous blood draw and serum lactate level were determined using whole blood by i-STAT (Abbott Point-of-Care, Inc., Abbott Park, IL, USA) lactate analyzer. The reportable range is $0.30-20.00 \mathrm{mmol} / \mathrm{L}$, reference range of 0.36 $1.25 \mathrm{mmol} / \mathrm{L}$ arterial and $0.90-1.70 \mathrm{mmol} / \mathrm{L}$ venous. Per the package insert, lactate is measured amperometrically. The enzyme lactate oxidase, immobilized in the lactate biosensor, selectively converts lactate to pyruvate and hydrogen peroxide $\left(\mathrm{H}_{2} \mathrm{O}_{2}\right)$. The liberated hydrogen peroxide is oxidized at a platinum electrode to produce a current which is
Correspondence: Peter S. Pang, Department of Emergency Medicine, Indiana University School of Medicine, 720 Eskenazi Avenue, FOB 3rd Floor, 46202 Indianapolis, IN, USA.

Tel. +1.317.880.3900 - Fax: +1.317.880.0545

E-mail: ppang@iu.edu

Key words: Acute heart failure; Lactate; Emergency department; Hypoperfusion.

Contributions: KS, drafted the initial manuscript; LA and PSP, extensively edited the initial manuscript and all subsequent revisions; KS and LP were the primary research personnel collecting primary data; KS performed the primary analysis; $\mathrm{KS}$, LA, LP, and PSP all reviewed the final manuscript.

Conflict of interest: KS, LA, and LP declare no potential conflict of interest; PSP reports that in the last 12 months, he is or has been or received consultant for Intersection Medical, INSYS, Janssen, Medtronic, Novartis, Trevena, scPharmaceuticals, Cardioxyl, Roche Diagnostics.

Acknowledgments: an Investigator Initiated Grant from Abbott Point of Care supported this work; the study design, database, data analysis, and final manuscript were independent from the sponsor.

Received for publication: 25 July 2015. Revision received: 26 October 2015. Accepted for publication: 26 October 2015.

This work is licensed under a Creative Commons Attribution 4.0 License (by-nc 4.0).

(C) Copyright K. Sauser et al., 2016

Licensee PAGEPress, Italy

Emergency Care Journal 2016; 12:5458

doi:10.4081/ecj.2016.5458

proportional to the sample lactate concentration. While venous or arterial blood may be sampled, for our study, capillary whole blood was used. Initial lactate level was determined within 8 hours of ED presentation, and a follow-up level was measured at 6-12 hours from first measurement. Demographic, clinical, and physical exam characteristics were also collected either primarily or through review of the medical record.

\section{Objectives}

Our primary outcome was lactate elevation at time of initial assessment. Lactate level $<2$ $\mathrm{mmol} / \mathrm{L}$ was defined as normal a priori, based on literature where lactate level of 2 or higher was associated with worse outcomes. ${ }^{5}$ Our secondary objective was to examine lactate clearance in the subset of patients with an initial elevated lactate. 
Table 1. Baseline patient characteristics.

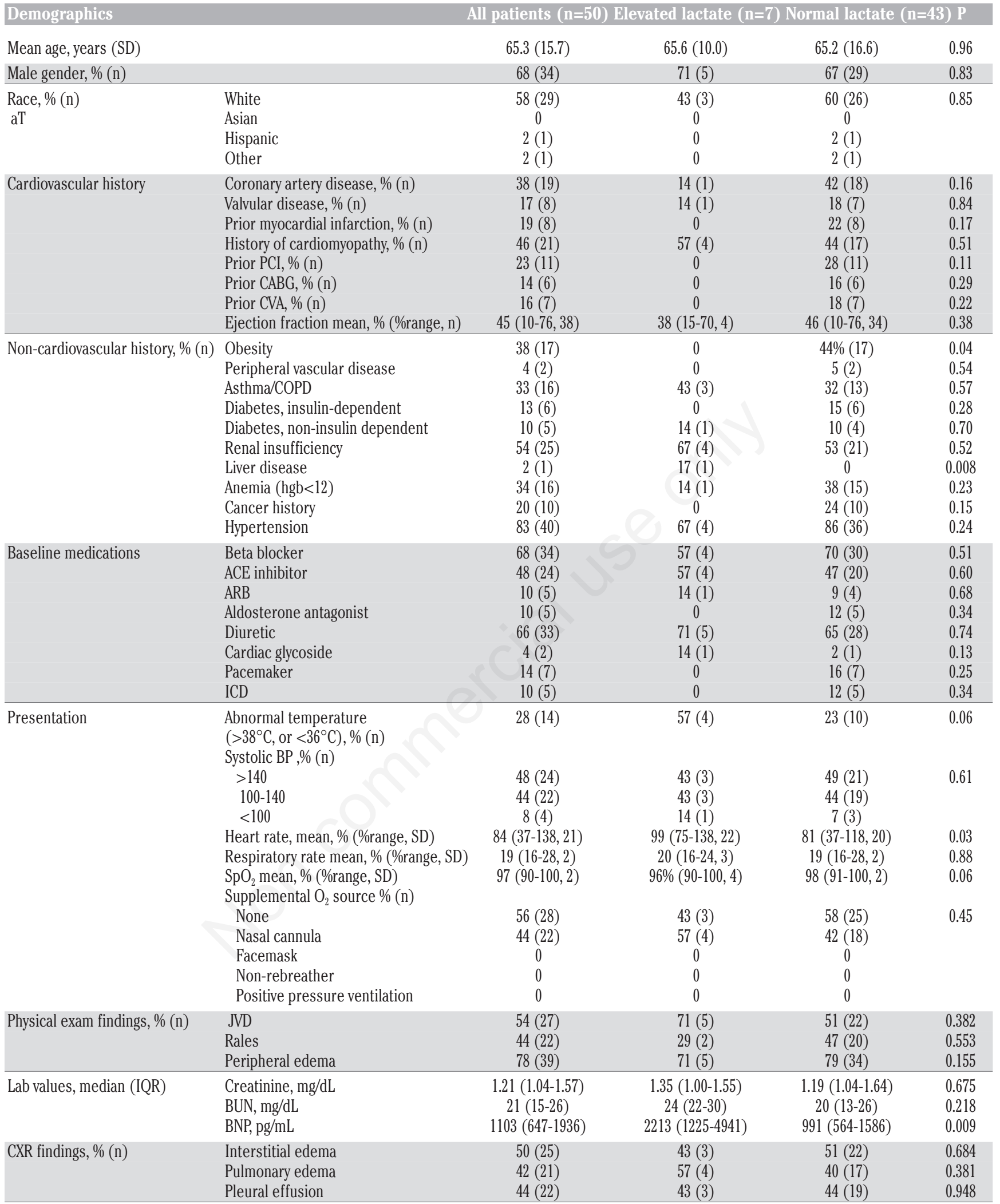

SD, standard deviation; $\mathrm{PCI}$, percutaneous coronary intervention; CABG, coronary artery bypass grafting; CVA, cerebrovascular accident; COPD, chronic obstructive pulmonary disease; hgb, hemoglobin; ACE, angiotensin-converting-enzyme; ARB, angiotensin receptor blocker; ICD, implantable cardioverter defibrillator; BP, blood pressure; JVD, jugular venous pressure; IQR, interquartile range; BUN, blood urea nitrogen; BNP, B-type natriuretic peptide; CXR, chest x-ray. 
Table 2. Characteristics of patients with elevated lactate levels.

\begin{tabular}{|c|c|c|c|c|c|c|}
\hline Patients & Age (years) & Gender & Brief history & $\begin{array}{l}\text { Characteristics } \\
\text { Exam }\end{array}$ & Lactate levels & Hospital course \\
\hline 1 & 69 & M & $\begin{array}{l}\text { History of HF, } \\
\text { afib, s/p MVR, } \\
\text { presented with } \\
\text { fatigue and dyspnea } \\
\text { on exertion, EF=30\% }\end{array}$ & $\begin{array}{l}\mathrm{T}=97.6 \mathrm{~F}, \mathrm{BP}=124 / 95 \\
\mathrm{HR}=91 \text { in afib, } 98 \% \text {, } \\
\text { signs of congestion (JVD) }\end{array}$ & $2.05,2.46$ & $\begin{array}{l}\text { In the ED, diuresed with lasix } 40 \mathrm{mg} \text { IV. } \\
\text { Admitted to the general medicine } \\
\text { floor for heart failure exacerbation, } \\
\text { no additional HF therapies initiated } \\
\text { aside from resumption of } \\
\text { patient's home meds, discharged on } \\
\text { HD \#2 }\end{array}$ \\
\hline 2 & 73 & M & $\begin{array}{l}\text { History of COPD, } \\
\text { alcoholic cirrhosis, } \\
\text { hypothyroidism } \\
\text { (no history of HF), } \\
\text { presented with SOB } \\
\text { and dyspnea on exertion }\end{array}$ & $\begin{array}{l}\mathrm{T}=95.1 \mathrm{~F}, \mathrm{BP}=93 / 68,98 \% \text {, } \\
\mathrm{HR}=138, \text { signs } \\
\text { of congestion } \\
\text { (crackles, LEE) }\end{array}$ & $2.49,1.84$ & $\begin{array}{l}\text { In the ED, diuresed with bumex } 1 \mathrm{mg} \text { IV, } \\
\text { also empirically treated for community } \\
\text { acquired pneumonia with antibiotics, } \\
\text { and given a therapeutic dose of LMWH } \\
\text { for suspected PE. Admitted to the CCU } \\
\text { after developing hypotension in the ED. } \\
\text { Echography performed on HD\#2 } \\
\text { demonstrated EF 20\% and Grade II-III } \\
\text { diastolic dysfunction. Underwent LHC } \\
\text { given new HF, no obstructive CAD. } \\
\text { Determined to have likely alcohol } \\
\text { induced vs tachycardia induced ca } \\
\text { diomyopathy. Patient had a hospital } \\
\text { course complicated by hypotension, } \\
\text { atrial fibrillation with RVR, delirium, } \\
\text { thrombocytopenia, and urinary } \\
\text { retention. Discharged on HD\#20 }\end{array}$ \\
\hline 3 & 70 & M & $\begin{array}{l}\text { History of DM2, HTN } \\
\text { (no history of HF), } \\
\text { presented with cough } \\
\text { and leg swelling }\end{array}$ & $\begin{array}{l}\mathrm{T}=96.6 \mathrm{~F}, \mathrm{BP}=127 / 79, \\
\mathrm{HR}=114 \text { in afib, } 95 \%, \mathrm{X} \\
\text { signs of congestion (LEE) }\end{array}$ & $1.79,2.08$ & $\begin{array}{l}\text { In ED, diuresed with lasix } 20 \text { mg IV, } \\
\text { hypokinesia with EF<25\%, } \\
\text { Grade III diastolic dysfunction. } \\
\text { Admitted to general medicine floor for } \\
\text { evaluation and management of new } \\
\text { heart failure and afib with RVR. Started } \\
\text { on lasix gtt for diuresis, and bridged } \\
\text { with heparin to oral anticoagulant for } \\
\text { new afib. Underwent RHC and LHC } \\
\text { demonstrating significant CAD w } 75 \% \\
\text { lesion in left main coronary artery, } \\
\text { CABG recommended. Underwent } \\
\text { extensive pre-operational evaluation as } \\
\text { an inpatient, discharged home with } \\
\text { LifeVest on HD\# } 12 \text {. Readmitted for } \\
\text { planned CABG and Maze procedure } 9 \\
\text { days later }\end{array}$ \\
\hline 4 & 60 & $\mathrm{~F}$ & $\begin{array}{l}\text { History of HTN, COPD } \\
\text { (no history of HF), } \\
\text { presented with SOB, } \\
\text { cough and leg swelling }\end{array}$ & $\begin{array}{l}\mathrm{T}=97.1 \mathrm{~F}, \mathrm{BP}=186 / 108, \\
\mathrm{HR}=121,99 \% \text {, } \\
\text { signs of congestion } \\
\text { (crackles, LEE) }\end{array}$ & $1.08,2.20$ & $\begin{array}{l}\text { In ED, diuresed with lasix } 20 \mathrm{mg} \text { IV, had } \\
\text { been given sublingual nitro } \\
400 \text { mcg by EMS prior to arrival. } \\
\text { Also received } 1 \text { duoneb for cough/SOB. } \\
\text { Echography performed in ED } \\
\text { demonstrated dilated cardiomyopathy } \\
\text { with EF=10-15\%. Admitted to cardiology } \\
\text { initiated on lasix } 40 \text { mg IV BID. Hospital } \\
\text { course complicated by DVT, stayed } \\
\text { inpatient to titrate oral anticoagulant } \\
\text { dose, threatened to leave AMA on } \\
\text { multiple occasions. Discharged on } \\
\text { HD\#14, stated to her team upon } \\
\text { dicharge that she planned to be } \\
\text { non-compliant with her medications }\end{array}$ \\
\hline
\end{tabular}


Table 2. Continued from previous page

\begin{tabular}{|c|c|c|c|}
\hline Patients & Age (years) Gender & Brief history & $\begin{array}{l}\text { Characteristics } \\
\text { Exam }\end{array}$ \\
\hline 5 & 78 & $\begin{array}{l}\text { History of CHF, HTN, } \\
\text { presented with SOB. } \\
E F=30-35 \%\end{array}$ & $\begin{array}{l}\mathrm{T}=94.6 \mathrm{~F}, \mathrm{BP}=152 / 122 \text {, } \\
\mathrm{HR}=105,100 \% \text {, } \\
\text { signs of congestion } \\
\text { (hepatomegaly, LEE) }\end{array}$ \\
\hline
\end{tabular}

$\begin{array}{ll}61 \quad \text { F } & \text { History of CHF, } \\ & \text { sarcoidosis, pulmonary } \\ & \text { HTN, presented with } \\ & \text { leg swelling and cough. } \\ & \mathrm{EF}>70 \%\end{array}$
$\mathrm{T}=97.2 \mathrm{~F}, \mathrm{BP}=131 / 74$,
$\mathrm{HR}=83,87 \%$,
signs of congestion
(JVD, LEE)

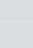

\section{Lactate levels Hospital course}

$1.84,2.83$ (hepatomegaly, LEE)
History of nonischemic cardiomyopathy, CHF, atrial flutter, presented to EP clinic with vomiting and epigastric pain, sent to ED by EP medical doctor due to concern for digoxin toxicity. $\mathrm{EF}=15 \%$

\author{
$\mathrm{T}=95.8 \mathrm{~F}, \mathrm{BP}=150 / 107$, \\ $\mathrm{HR}=121$ in afib, $98 \%$, \\ $1.87,2.83$ \\ signs of \\ congestion (LEE) \\ In the $\mathrm{ED}$, given diltiazem $10 \mathrm{mg}$ \\ IV for afib with RVR, no diuretics \\ or nitrates administered. \\ Digoxin level obtained and was \\ within normal limits (1.9). Patient \\ admitted to the inpatient \\ cardiology service for management \\ of heart failure exacerbation and afib \\ w RVR. Daily diuresis with IV lasix, \\ bumex; initially on IV anticoagulant \\ therapy for afib while cardiology service \\ considered cardioversion, but TTE \\ demonstrated thrombus, so patient \\ bridged to oral anticoagulant as an \\ inpatient and discharged on HD\#5 with \\ plan to return to EP clinic for scheduled \\ outpatient cardioversion
}

$1.06,3.13$

In ED, diuresed with lasix $40 \mathrm{mg}$ IV and given home dose of $\mathrm{PO}$ antihypertensives, but persistently hypertensive so given nitropaste. Admitted to general medicine floor, underwent diuresis with bumex IV BID and bumex gtt. Had HF and HTN meds titrated as an inpatient. Discharged on HD\# 7

In ED, diuresed with lasix $80 \mathrm{mg} I V$, placed on $40 \% \mathrm{FiO} 2$ via face mask for low 02 saturations. CTA in ED negative for PE. MICU consulted given supplemental $\mathrm{O} 2$ requirement, determined patient stable for admission to general medicine floor. Admitted to general medicine floor for lasix gtt and titration of HF and pulmonary HTN medications, with pulmonary service following. Echography obtained as inpatient demonstrated severe, worsened pulmonary HTN. On HD\#4, transferred to the MICU for tachypnea, increasing $\mathrm{O} 2$ requirement, increased WOB and fever. Upon transfer to MICU was placed on BiPAP, treated for HCAP with antibiotics, and continued on treatment for HF and pulmonary HTN. Respiratory status failed to improve in the MICU, but patient decided she did not want to be on BiPAP at home. Transitioned back to $5 \mathrm{~L}$ nasal cannula and seen by palliative care. Patient elected to go home from the MICU and at the time of discharge on HD\#10 was considering hospice care

$\mathrm{HF}$, heart failure; afib, atrial fibrillation; MVR, mitral valve replacement; $\mathrm{EF}$, ejection fraction; T, temperature; BP, blood pressure; HR, heart rate; ED, emergency department; JVD, jugular venous pressure; IV, intravenous; HD, hospital day; COPD, chronic obstructive pulmonary disease; SOB, shortness of breath; LMWH, low-molecular-weight heparin; PE, pulmonary embolism; CCU, coronary care unit; LHC, left heart catheterization; CAD, coronary artery disease; RVR, rapid ventricular rate or response; DM2, type 2 diabetes; HTN, hypertension; RHC, right heart catheterization; CABG, coronary artery bypass graft surgery; EMS, emergency medical system; BID, twice a day; DVT, deep vein thrombosis; AMA, against medical advice; CHF, chronic heart failure; CTA, computed tomography angiography; MICU, medical intensive care unit; WOB, work of breathing; BiPAP, bi-level positive airways pressure; HCAP, healthcare-associated pneumonia; EP, electrophysiology; TTE, transthoracic echocardiogram. 


\section{Data analysis}

Our sample size of 50 patients was determined based on logistical and budgetary constraints. Using a one-tailed estimate, $80 \%$ power, and an alpha of 0.05 , this sample size was powered to show an effect size of $33 \%$ comparing the proportion of patients with and without elevated lactate. Patients were divided into elevated ( $\geq 2 \mathrm{mmol} / \mathrm{L}$ ) or normal lactate groups. Due to small number of patients with elevated lactate levels, patients were included in the elevated group if they had an elevated lactate on either of the two blood draws. Comparisons between groups were done with student's t-test, chi-square test, and ANOVA as appropriate. Given the small number of patients with elevated lactate levels, repeated measures analysis was not performed.

\section{Results}

Of the 50 patients enrolled, $68 \%$ were male, $58 \%$ white, with a mean age of 65.3 years (standard deviation=15.7 years) (Table 1). Mean ejection fraction was $45 \%$ (range 10 $76 \%$ ), and the majority of patients were on a beta-blocker or a diuretic (68 and $66 \%$ respectively).

Seven patients had an elevated lactate level on either blood draw. Two patients had elevated lactate on the first blood draw, within 8 hours of ED presentation. One of those patients had a persistently elevated lactate on second blood draw 6-12 hours later, and 5 other patients had a newly elevated lactate on second draw. Patients were similar in cardiovascular and non-cardiovascular medical history, and in historical heart failure medications.

Characteristics of patients in the elevated lactate group are presented in Table 2, with brief summaries of history and hospital course. Of the 7 patients with elevated lactate, 4 were male, and ages ranged from 48-78 years. Three of the 7 patients had no previously documented diagnosis of heart failure. None of the patients had systolic blood pressure less than $90 \mathrm{mmHg}$ on ED arrival. Patients with an elevated lactate had a higher mean heart rate (99 vs 81, $\mathrm{P}=0.03$ ) and trended toward an increased rate of hypothermia ( 57 vs $23 \%$ with either hyper or hypothermia, $\mathrm{P}=0.06$ ). Six patients were admitted to the floor, and one to the coronary care unit; one patient was admitted to the floor and later transferred to the medical intensive care unit for respiratory distress. With the exception of one patient who developed pneumonia on hospital day four
(Table 2), no patients were diagnosed with infection during the course of hospitalization. Hospital length of stay ranged 2-20 days (median 10 days). All patients survived hospitalization.

\section{Discussion}

The burden of acute heart failure has been well described. ${ }^{1,6}$ Hospitalization consumes the largest portion of financial resources spent on heart failure every year, and are independently associated with a worse outcome. ${ }^{6}$ EDs are the primary gateway for these admissions, yet the role of the ED in the management of AHF and its impact on downstream care or outcomes has not been well studied. ${ }^{7}$ Small studies or retrospective analyses highlight the importance of timely intervention, suggesting a time-dependent pathogenic mechanism. As such, we sought to better understand the early pathophysiology of AHF through a pilot study of lactate levels over time to explore whether hypoperfusion might inform our understanding of AHF in the ED. Only a minority of patients presenting to the ED with AHF had elevated lactate levels. Although the study is limited by small sample size, overall our results suggest that the hemodynamic and neurohormonal derangements present in acute heart failure do not consistently lead to hypoperfusion sufficient to elevate lactate levels. This is in marked contrast to Ander and colleagues' study where the majority of patients enrolled, although also a convenience sample, had elevated lactate levels. ${ }^{4}$ This may be due to differences in the patient populations. Most of our patients had an EF $>40 \%$, whereas in the Ander and colleagues' study, the mean EF was $16 \%$.

Elevated lactate levels are most commonly associated with shock states, given their rise due to ischemia from hypoperfusion. However, we focused on a more general AHF population to determine whether sub-clinical hypoperfusion might be a pathologic finding. This hypothesis was informed by data suggesting that organ injury or dysfunction occurs in AHF outside of cardiogenic shock or clear hypoperfusion states. ${ }^{2}$ Although great caution is warranted regarding conclusions from a limited sample, the fact that 5 patients had elevated lactate levels despite normal levels at baseline suggests that either patients worsened, required more aggressive management initially or during hospitalization, or reflects a unique pathophysiology of worsening perfusion despite appropriate treatment.

The small number of enrolled patients and utilization of a convenience sample from a single center are major limitations with a strong risk for Type II error. Also, samples were drawn within 8 hours of presentation. Thus, treatment may have impacted lactate levels.

\section{Conclusions}

In this pilot study, elevated lactate levels were rarely seen at baseline or soon after hospitalization. In those patients with elevated lactate, the elevation was more likely to occur after initial treatment. While this may be a chance finding, it was unexpected given that AHF patients presumably would be at greatest risk at the time of presentation. Given the small sample size, any conclusion should be interpreted with caution; still, this may represent an avenue for further investigation.

\section{References}

1. Yancy CW, Jessup M, Bozkurt B, et al. 2013 ACCF/AHA Guideline for the management of heart failure: a report of the American College of Cardiology Foundation/American Heart Association Task Force on Practice Guidelines. J Am Coll Cardiol 2013;62:147-239.

2. Metra M, Cotter G, Davison BA, et al. Effect of serelaxin on cardiac, renal, and hepatic biomarkers in the Relaxin in Acute Heart Failure (RELAX-AHF) development program: correlation with outcomes. J Am Coll Cardiol 2013;61:196-206.

3. Jansen TC, van Bommel J, Bakker J. Blood lactate monitoring in critically ill patients: a systematic health technology assessment. Crit Care Med 2009;37:2827-39.

4. Ander DS, Jaggi M, Rivers E, et al. Undetected cardiogenic shock in patients with congestive heart failure presenting to the emergency department. Am J Cardiol 1998;8:888-91.

5. Mikkelsen ME, Miltiades AN, Gaieski DF, et al. Serum lactate is associated with mortality in severe sepsis independent of organ failure and shock. Crit Care Med 2009;37:1670-7.

6. Go AS, Mozaffarian D, Roger VL, et al. Heart disease and stroke statistics - 2014 update: a report from the American Heart Association. Circulation 2014;129:2-267.

7. Pang PS, Schuur JD. Emergency departments, acute heart failure, and admissions: one size does not fit all. J Am Coll Cardiol 2014;2:278-80. 